American Journal of Applied Sciences 8 (2): 134-140, 2011

ISSN 1546-9239

(C) 2010 Science Publications

\title{
Personality Traits as Predictors towards Readiness to Change among Female Drug Addicts
}

\author{
W.S. Wan Shahrazad, Z.M. Lukman, A.R. Roseliza Murni, A.Z. Zainah, \\ I. Fauziah and Z. Arifin \\ School of Psychology and Human Development, Faculty of Social Sciences and Humanities, \\ Universiti Kebangsaan Malaysia, 43600 UKM Bangi, Selangor, Malaysia
}

\begin{abstract}
Problem statement: Understanding the personality traits among women who are involved in drug addiction is a crucial issue prior to starting any intervention programs. It may provide an indication of their readiness to receive treatment and change this addictive behavior. This study was conducted to examine the predictive relationship between personality traits and readiness to change among women drug addicts in Malaysia. Approach: The study employed survey research involving the administration of two standardized psychological tests which were the Eysenck Personality Questionnaire Revised Short Version (EPQ-RS) and the Stages of Change Readiness and Treatment Eagerness Scale (SOCRATES). A total of 109 female drug addicts who were undergoing drug treatment in a female rehabilitation center in Malaysia participated in this study. Data were analyzed using Pearson correlation and multiple regression analysis. Results: The current study shows that there were significant correlations between the traits of extraversion, neuroticism and psychoticism with all the three stages of readiness to change. The study also demonstrated that high extraversion and neuroticism traits significantly predicted the recognition subscale. Conclusion: Being high on neuroticism and low in psychoticism traits significantly predicted the respondents to be ambivalence about changing their addictive behaviors. Likewise, being high on extraversion and neuroticism as well as low on psychoticism significantly predicted the taking steps subscale.
\end{abstract}

Key words: Personality traits, readiness to change, drug addiction, addictive behavior, regression analysis, neuroticism traits, significant correlations

\section{INTRODUCTION}

Drug abuse and addiction are among the most pressing health and social issues facing Malaysia, resulting in serious health risks. Although extraordinary progress has been made in understanding these disorders and in finding the best ways to prevent and treat them, unfortunately, research on drug abuse and addiction related to women has, until recently relatively been sorely neglected (Chang and Vigorito, 2006; Wetherington, 1999). The increasing rate of drug addiction is observed not only among men but also among women. In Malaysia, the number of women who are involved in drug addiction and undergoing treatment in rehabilitation centers is $2.25 \%$ out of 10,977 total drug addicts (Agensi Anti Dadah Kebangsaan, 2008). Although their number is not as high as those of male drug addicts, nevertheless it is significant enough for the Malaysian government to establish a separate rehabilitation center for women. From a total of 27 rehabilitation centers in Malaysia, one of them is designed specifically for female addicts.

Drug dependency at personality level is profound and visible and they can therefore affect the personality when dependency has been installed for a while (Grana et al., 2009; Dévieux et al., 2009). A number of studies (Eysenck, 1997; Gerra et al., 2008; Ahmad and Hammoud, 2005) have shown that drug addiction is related to some specific personality traits, hence the term "addictive personality" (Eysenck, 1997). Most of the studies on drug addicts' personality traits were conducted on male respondents and they were reported to score significantly high on neuroticism and psychoticism traits while scored significantly low on extraversion and lie scale (Blaszczynski et al., 1985; Gossop and Eysenck, 1980). However, relatively little is known about the personality profile of female drug addicts as studies that focused specifically on this

Corresponding Author: Lukman Z.M., School of Psychology and Human Development, Faculty of Social Sciences and Humanities, Universiti Kebangsaan Malaysia, 43600 UKM, Bangi, Selangor, Malaysia 
population is lacking. According to Eysenck and Eysenck (1985) the personality profiles of males and females are different. Thus, it is possible that the personality traits belonging to female drug addicts are different than those of their male counterparts. This also raises the question regarding the types of personality traits that could be considered as the predisposing factors toward addiction among women and how are they related to a person's readiness for changing their addictive behaviors (Ahmad and Hammoud, 2005).

An addict's motivation and readiness for change has been postulated to be an important component toward successful treatment (Friedman et al., 1994). In fact, within substance abuse treatment an addict's motivation and readiness to change has become an important prerequisite for a successful treatment. Consequently, the lack of motivation and readiness to change has often been used to explain the failure to begin, continue and comply with the treatment (Miller and Rollnick, 1991). Within the context of Malaysia, Fauziah and Kumar (2009) found that the lack of motivation and readiness to change among the drug addicts were one of the key factors that contributed toward relapse cases. Although, it is clear that a person's motivation and readiness to change has become one of the important components that determined the success of a drug treatment program, we are still uncertain about what predicts the addicts' motivation and readiness to change their addictive behaviors (Zebun, 2009).

Therefore, the objective of this study is to examine the correlation between personality traits and readiness to change. It also attempts to examine the predictive relationship between extraversion, neuroticism and psychoticism with recognition, ambivalence and taking steps subscales. The hypotheses tested are: (1) There are significant correlations between extraversion, neuroticism and psychoticism with the three components of readiness to change; (2) Recognition is significantly predicted by extraversion, neuroticism and taking steps; (3) Ambivalence is significantly predicted by extraversion, neuroticism and taking steps; and (4) Taking steps is significantly predicted by the traits of extraversion, neuroticism and psychoticism.

Female drug addicts, personality and readiness to change: Studies of personality profiles of heroine addicts using Eysenck Personality Questionnaire (EPQ; Eysenck and Eysenck, 1975) showed that they have different personality profiles from subjects who were not drug addicts (Blaszczynski et al., 1985; Gossop and Eysenck, 1980; Nishith et al., 1994). Gossop and
Eysenck (1980) who used EPQ-Addiction Scale among 221 drug addicts showed that the personality of polydrug users (in which majority of them reported that they preferred heroine), can be differentiated with the personality of a normal control group. Drug addicts were found to obtain significantly high scores in psychoticism (P) and neuroticism (N) scales, but obtained significantly low scores in extraversion (E) and lie scales (L). The same findings were obtained by Blaszczynski et al. (1985) who studied a group of heroine addicts in Australia.

The study conducted by Carey et al. (2002) showed that the main reason for the clients' failure to change their drug behavior was due to the lack of motivation. The "self-determination theory" proposed that the formation of human behavior can be influenced by internal and external factors. The formation of behavior that is influenced by internal instinct factors will cause lasting behavioral changes compared with the changes in behavior caused by the external factors (Deci and Ryan, 2000).

On a separate issue, gender differences among drug users concerning the patterns of treatment utilization or the development and maintenance of a " "treatment career"' have also been observed (Hser et al., 1997). Women and men differed in terms of when they initiate treatment, the sources of referral and social support for entering treatment and where they accessed treatment (Brennan et al., 1993; Weisner and Schmidt, 1992). Women reported a briefer transition from first drug use to addiction and tended to enter treatment sooner than men, that is, after a briefer period of regular drug use (Chang and Vigorito, 2006; Anglin et al., 1987; Hser et al., 1997). Among a sample of individuals hospitalized for cocaine dependence, women had a more rapid development of dependency, first entered treatment at a younger age and were more likely to have a drug-dependent partner than the men (Griffin et al., 1989).

There is a growing awareness in the treatment retention literature of gender differences that may differentially affect retention for women (Weisdorf et al., 1999). Women were more likely than men to enter treatment (Schutz et al., 1994) and to engage in drug treatment (Fiorentine et al., 1997). Some studies showed that women tended to be less likely than men to remain in drug treatment (De Leon, 1984; Knight and Hiller, 1997; Sansone, 1980), whereas other reports have found no relationship (Simpson et al., 1997; Fishman et al., 1999). Women's programs that offered specialized services or interventions (Weisdorf et al., 1999; Hser et al., 2001; Knight et al., 2001) were found to have higher retention rates. Research, however, has 
not systematically addressed the question of gender differences in treatment entry and treatment retention.

According to Dawson (1996), Schober and Annis (1996) and Walitzer and Connors (1997), women are less likely than men to seek treatment for substance abuse problems. These researchers hypothesized that women sought substance abuse treatment less often than men because they experienced: (a) more frequent barriers to treatment, such as childcare responsibilities, inadequate health insurance and poverty (Hodgins et al., 1997); (b) cultural norms that resulted in greater stigma for women's addictions (Center for Substance Abuse Treatment, 1994; Thom, 1987); and (c) inconsistencies between female gender roles and the health problem for which services are being sought, such as conflicts between the "mother" role and seeking assistance for drug abuse problems (Russo and Sobel, 1981).

Fauziah et al. (2010) studied 593 people from six drug rehabilitation centers in Peninsular Malaysia who responded to a survey by using stratified random sampling and systematic random sampling. Results indicate that majority of respondents reported high readiness in terms of recognition and taking steps to change and recover from the drug. On the other hand, the results also showed that majority of the drug addicts were still ambivalent and therefore were not sure whether they can control the problems associated with drug addiction.

A study conducted by Wan Shahrazad et al. (2010) on 599 drug addicts undergoing treatment demonstrated that the addicts' personality traits turned out to be one of the influential factors in determining their readiness to change the addictive behavior. Results of this study revealed that high level of neuroticism trait and low level of psychoticism trait significantly determined the addicts' readiness to change their addictive behaviors. The significant and negative correlation between psychoticism and readiness to change suggested that the rehabilitees who reported high readiness to change tended to have less tendencies for hostility and aggression, but are more sensitive to the needs of others. The finding of the study also indicated that the trait of psychoticism must be low in order for rehabilitees to start taking steps in changing their addiction.

\section{MATERIALS AND METHOD}

This study was conducted by using a survey design in which two standardized questionnaires were administered. A total of 109 rehabilitees from one drug rehabilitation centers comprising of female drug addicts agreed to participate in this research. The instruments used were two standardized psychological tests which were:

- Eysenck Personality Questionnaire Revised Short Version (EPQ-RS: Eysenck et al., 1985). The questionnaire consists of 48 items using binary format, YES or NO. It measures four scales which are Neuroticism, Extraversion, Psychoticism and Lie

- The Stages of Change Readiness and Treatment Eagerness Scale (SOCRATES). SOCRATES is a psychological measurement to measure three subscales which are Recognition, Ambivalence and Taking Steps

The EPQ-RS was reported to have good reliability for all subscales between 0.76 to 0.90 (Eysenck et. al., 1985). The questionnaire was translated to Malay language using back translation method and found satisfactory reliability with alpha Cronbach ranging from .301 to .754 for male respondents and from .444 to .764 for female respondents.

The SOCRATES was also reported to have good alpha reliability between .60-.88 for Ambivalence, .85.95 for Recognition and .83-.96 for Taking Steps (Miller and Tonigan, 1996). In addition, test retest reliability also showed high values of .82 for Ambivalence, .88 for Recognition and .91 for Taking Steps. The Malay version back translated SOCRATES also showed satisfactory reliability which were .808 for Ambivalence, .660 for Recognition and .832 for Taking Steps (Arifin et al., 2010).

The research was conducted by first getting permission from the National Anti Drugs Agency (NADA). Once approval was obtained, the researchers administered the questionnaires to participants identified by officials in the drug rehabilitation centers. Instructions were given to participants and items were explained to participants when necessary. All the completed questionnaires were then collected by researchers. The data were keyed in and analyzed using Statistical Package for Social Sciences (SPSS). Statistical analyses employed were Pearson correlation and multiple regression analysis (Ramzi and Naimy, 2010).

\section{RESULTS AND DISCUSSION}

The findings in this research for all the hypotheses are presented here. Hypothesis 1 was formulated to examine the relationship between personality traits of extraversion, neuroticism and psychoticism with readiness to change. Results in Table 1 showed that 
Am. J. Applied Sci., 8 (2): 134-140, 2011

Table 1: Correlations between personality traits and readiness to change

\begin{tabular}{lccr}
\hline & Recog. & Ambiv. & T.Steps \\
\hline Extraversion & $0.314^{*}$ & $0.207^{*}$ & $0.323^{*}$ \\
Neuroticism & $0.381^{*}$ & $0.381^{*}$ & $0.278^{*}$ \\
Psychoticism & $-0.228^{*}$ & $-0.298^{*}$ & $-0.399^{*}$ \\
\hline$*:$ p $<0.05$ & & &
\end{tabular}

*: $\mathrm{p}<0.05$

Table 2: Multiple regression analysis between extraversion, neuroticism and psychoticism with recognition

\begin{tabular}{lrlcc}
\hline Model & \multicolumn{1}{c}{ B } & Std. Error & Beta & $\mathrm{t}$ \\
\hline Constant & 17.99 & 1.88 & & $8.56^{*}$ \\
Extra & 0.39 & 0.16 & 0.23 & $2.52^{*}$ \\
Neuro & 0.49 & 0.13 & 0.34 & $3.86^{*}$ \\
Psycho & -0.58 & 0.22 & -0.12 & -1.27 \\
\hline * $p<0.05$ & & & &
\end{tabular}

there were significant and positive correlations between extraversion with recognition, ambivalence and taking steps. This meant that the higher the scores of extraversion the higher the readiness of rehabilitees to change. There were also significant and positive correlations between neuroticism with recognition, ambivalence and taking steps. The results indicated that the higher the scores of neuroticism which measured emotional instability the higher the readiness of rehabilitees to change. On the other hand, there were significant and negative correlations between psychoticism with recognition, ambivalence and taking steps. Lower scores in psychoticism indicated that the rehabilitees have higher readiness to change.

The second hypothesis regarding recognition subscale, were found to be significantly predicted by personality traits. Result of multiple regression showed that extraversion and neuroticism predicted significantly recognition with $23 \%$ variance, $\mathrm{R}^{2}=.23$, $F(3,105)=10.24, p<.0001$. The linear equation that can be formulated is:

$$
\mathrm{Y}=17.99+.39(\text { Extraversion })+.49(\text { Neuroticism })
$$

Extraversion was a significant predictor with Beta=.23, $\mathrm{t}=2.52, \mathrm{p}<.05$. Similarly, neuroticism also significantly predicted recognition with Beta=.34, $\mathrm{t}=-$ 3.86, $\mathrm{p}<.0001$. The results are shown in Table 2.

The third hypothesis investigated the predictive relationship between extraversion, neuroticism and psychoticism towards ambivalence. The regression model also showed that neuroticism and psychoticism predicted significantly ambivalence with $22 \%$ variance, $\mathrm{R}^{2}=.22, \mathrm{~F}(3,105)=9.70, \mathrm{p}<.0001$. The linear equation that can be formulated is:

$$
\mathrm{Y}=13.19+.33(\text { Neuroticism) }-.37 \text { (Psychoticism) }
$$

Neuroticism was a significant predictor with Beta $=.34, \mathrm{t}=3.92, \mathrm{p}<.0001$. Similarly, psychoticism
Table 3: Multiple regression analysis between extraversion, neuroticism and psychoticism with ambivalence

\begin{tabular}{lrlcc}
\hline Model & \multicolumn{1}{c}{$\mathrm{B}$} & Std. Error & Beta & $\mathrm{t}$ \\
\hline Constant & 13.19 & 1.24 & & $10.61^{*}$ \\
Extra & 0.10 & 0.10 & 0.09 & 0.93 \\
Neuro & 0.33 & 0.08 & 0.34 & $3.91^{*}$ \\
Psycho & -0.37 & 0.15 & -0.23 & $-2.52^{*}$ \\
\hline
\end{tabular}

$*: \mathrm{p}<0.05$

Table 4: Multiple regression analysis between extraversion, neuroticism and psychoticism with taking steps

\begin{tabular}{lrlrr}
\hline Model & $\mathrm{B}$ & Std. Error & Beta & $\mathrm{t}$ \\
\hline Constant & 29.08 & 2.37 & & $2.25^{*}$ \\
Extra & 0.42 & 0.20 & 0.19 & $2.15^{*}$ \\
Neuro & 0.40 & 0.16 & 0.21 & $2.50^{*}$ \\
Psycho & -0.96 & 0.28 & -0.31 & $-3.48^{*}$ \\
\hline
\end{tabular}

*: $p<0.05 a l s o$

significantly predicted ambivalence with Beta $=-.23$, $\mathrm{t}=-2.52, \mathrm{p}<.05$. The results are shown in Table 3 .

Finally, the fourth hypothesis on the predictive relationship between extraversion, neuroticism and psychoticism towards taking steps was accepted. The regression model showed that extraversion, neuroticism and psychoticism predicted significantly taking steps with $25 \%$ variance, $\mathrm{R}^{2}=.25, \mathrm{~F}(3,105)=11.45$, $\mathrm{p}<$ .0001 . The linear equation that can be formulated is:

$$
\begin{gathered}
\mathrm{Y}=29.08+.42(\text { Extraversion })+.40(\text { Neuroticism })-.96 \\
\text { (Psychoticism) }
\end{gathered}
$$

Extraversion was a significant predictor with Beta $=.19, \mathrm{t}=2.15, \mathrm{p}<.05$. Neuroticism was also a significant predictor with Beta=.21, $\mathrm{t}=2.50, \mathrm{p}<.05$. Similarly, psychoticism also significantly predicted taking steps with Beta=-.31, $\mathrm{t}=-3.48, \mathrm{p}<.0001$. In this subscale, psychoticism is the strongest predictor compared to extraversion and neuroticism. The results are shown in Table 4.

\section{CONCLUSION}

Results of correlation showed that all personality traits of extraversion, neuroticism and psychoticism were significantly correlated with the readiness to change. Extraversion and neuroticism were significant predictors of recognition to change, while neuroticism and psychoticism predicted significantly ambivalence. This suggests that those who were emotionally unstable and have high psychoticism trait were still ambivalent about changing their addictive behavior. In addition, psychoticism trait indicated the characteristics of impulsivity, failure to give attention and disorganized personality (Eysenck, 1997).

More importantly, the significant contribution was highest in the subscale of taking steps. This meant that 
women who were undergoing treatment were already taking steps in changing their addiction. This pattern of significant prediction was similar in both recognition and ambivalence with neuroticism as the strongest predictor compared to psychoticism. However, in the stage of taking steps, psychoticism was the strongest predictor compared to neuroticism and extraversion. This finding indicated that the trait of psychoticism must be low in order for rehabilitees to start taking steps in changing their addiction. Finally, it is interesting to note that those who worry a lot were amongst the one who recognized that they have problems with their addictions (Dévieux et al., 2009; Yampolskiy, 2008). Nevertheless, they were also ambivalence about changing their addictive behavior.

\section{ACKNOWLEDGEMENT}

This research has been supported generously by the National Anti-Drugs Agency of Malaysia and the Faculty of Social Sciences and Humanities, Universiti Kebangsaan Malaysia. The researchers would like to express their sincere appreciation for all the support provided.

\section{REFERENCES}

Agensi Anti Dadah Kebangsaan, 2008. Laporan tahunan $08 . \quad$ Putrajaya: AADK. http://www.adk.gov.my/pdf/laporantahun08.pdf

Ahmad, H. and M. Hammoud, 2005. Addictive behaviors amongst university students: contributing factors, student's perception and addiction rates. J. Soc. Sci., 1: 105-113. DOI: 10.3844/jssp.2005.105.113

Anglin, M.D., Y.I. Hser and M.W. Booth, 1987. Sex differences in addict careers. 4. treatment. Am. J. Drug Alcohol Abuse, 13: 253-280.

Blaszczynski, A.P., N. Buhrich and N. McConaghy, 1985. Pathological gamblers, heroin addicts and controls compared on the E.P.Q.'addiction scale'. British J. Addiction, 80: 315-319. DOI: 10.1111/j.1360-0443.1985.tb02545.x

Brennan, P.L., R.H. Moos and J.Y. Kim, 1993. Gender differences in the individual characteristics and life contexts of late-middle-aged and older problem drinkers. Addiction, 88: 781-790. PMID: 8329969, DOI: 10.1111/j.1360-0443.1993.tb02092.x

Carey, K.B., M.P. Carey, S.A. Maisto and D.M. Purnine, 2002. The feasibility of enhancing psychiatric outpatients' readiness to change their substance use. Psychiatric Services, 53: 602-608. PMID: 11986511
Center for Substance Abuse Treatment, 1994. Practical approaches in the treatment of women who abuse alcohol and other drugs. 1st Edn., Department of Health and Human Services, Public Health Service, USA., ISBN-13: 978-0160452543, pp: 275.

Chang, S.L. and M. Vigorito, 2006. Role of HIV-1 infection in addictive behavior: A study of a HIV-1 transgenic rat model. Am. J. Infec. Dis., 2: 98-106. DOI: 10.3844/ajidsp.2006.98.106

Dawson, D.A., 1996. Gender differences in the probability of alcohol treatment. J. Substance Abuse, 8: 211-225. DOI: 10.1016/S08993289(96)90260-6

De Leon, G., 1984. Program-based evaluation research in therapeutic communities. NIDA Research Monograph, 51: 69-87. PMID: 6438519

Deci, E.L. and R.M. Ryan, 2000. The "what" and "why" of goal pursuits: human needs and the selfdetermination of behavior. Psycholog. Inquiry, 11: 227-268. DOI: 10.1207/S15327965PLI1104_01

Dévieux, J.G., R.M. Malow, R. Rosenberg, M. Nair and D.M. Samuels et al., 2009. Borderline personality symptoms and human immunodeficiency virus risk in alcohol and other drug abusing adolescent offenders. Am. J. Infect. Dis., 5: 31-39. DOI: 10.3844/ajidsp.2009.31.39

Eysenck, H.J. and M.W. Eysenck, 1985. Personality and Individual Differences: A Natural Science Approach. 1st Edn., Plenum Press, New York, ISBN-13: 9780306418440, pp: 424.

Eysenck, H.J. and S.B.G. Eysenck, 1975. Manual of the Eysenck Personality Questionnaire (Junior and Adult). 1st Edn., Hodder and Stoughton, UK., pp: 47.

Eysenck, H.J., 1997. Addiction, personality and motivation. Human Psychopharmacology, 12: 79-87. DOI: $10.1002 /($ SICI)10991077(199706)12:2+<S79::AIDHUP905>3.0.CO;2-T

Eysenck, S.B.G., H.J. Eysenck and P. Barrett, 1985. A revised version of the psychoticism scale. Personality Individual Diff., 6: 21-29. DOI: 10.1016/0191-8869(85)90026-1

Fauziah, I. and N. Kumar, 2009. The influence of community on relapse addiction to drug use: Evidence from Malaysia. European J. Soc. Sci., 11: 471-476.

Fauziah, I., Z. Arifin, W.S.W. Shahrazad, Z.M. Lukman and A.R.R. Murni et al., 2010. Measuring motivational readiness for change among drug addicts in Malaysia: a descriptive analysis. Soc. Sci., 5: 429432. DOI: $10.3923 /$ sscience.2010.429.432

Fiorentine, R., M.D. Anglin, V. Gil-Rivas and E. Taylor, 1997. Drug treatment: explaining the gender paradox. Substance Use Misuse, 32: 653-678. PMID: 9178435 
Fishman, J., T. Reynolds and E. Reidel, 1999. A retrospective investigation of an intensive outpatient substance abuse treatment program. American Journal of Drug and Alcohol Abuse, 25(2): 185-196. PMID: 10395154

Friedman, A.S., S. Granick and C. Kreisher, 1994. Motivation of adolescent drug abusers for help and treatment. J. Child Adolescent Substance Abuse, 3: 69-88. DOI: 10.1300/J029v03n01_07

Gerra, G., S. Bertecca, A. Zaimovic, M. Pirani and B. Branchi et al., 2008. Relationship of personality traits and drug of choice by cocaine addicts and heroin addicts. Substance Use Misuse, 43: 317-330. PMID: 18365934

Gossop, M.R. and H.J. Eysenck, 1980. A further investigation into the personality of drug addicts in treatment. British J. Addiction, 75: 305-311. DOI: $10.1111 /$ j.1360-0443.1980.tb01384.x

Grana, J.L., J.J. Munoz and E. Navas, 2009. Normal and pathological personality characteristics in subtypes of drug addicts undergoing treatment. Personality individual Diff., 46: 418-423. DOI: 10.1016/j.paid.2008.11.011

Griffin, M.L., R.D. Weiss, S.M. Mirin and U. Lange, 1989. A comparison of male and female cocaine abusers. Arch. Gen. Psychiatry, 46: 122-126. PMID: 2913971

Hodgins, D.C., N. el Guebaly and J. Addington, 1997. Treatment of substance abusers: single or mixed gender programs? Addiction, 92: 805-812. DOI: 10.1111/j.1360-0443.1997.tb02949.x

Hser, Y.I., V. Joshi, M. Maglione, C.P. Chou and M.D. Anglin, 2001. Effects of program and patient characteristics on retention of drug treatment patients. Eval. Prog. Plann., 24: 331-341. DOI: 10.1016/S0149-7189(01)00027-1

Hser, Y.I., M.D. Anglin, C. Grella, D. Longshore and M.L. Prendergast, 1997. Drug treatment careers. a conceptual framework and existing research findings. J. Substance Abuse Treat., 14: 543-548. DOI: 10.1016/S0740-5472(97)00016-0

Knight, D.K., S.M. Logan and D.D. Simpson, 2001. Predictors of program completion for women in residential substance abuse treatment. Am. J. Drug Alcohol Abuse, 27: 1-18. PMID: 11373028 http://www.ncbi.nlm.nih.gov/pubmed/11373028

Knight, K. and M.L. Hiller, 1997. Community-based substance abuse treatment: A 1-year outcome evaluation of the Dallas County Judicial Treatment Center. Federal Probation, 61: 61-68.

Miller, W.R. and J.S. Tonigan, 1996. Assessing drinkers' motivations for change: The Stages of Change Readiness and Treatment Eagerness Scale (SOCRATES). Psychol. Addictive Behav., 10: 81-89. DOI: 10.1037/0893-164X.10.2.81
Miller, W.R. and S. Rollnick, 1991. Motivational Interviewing: Preparing People to Change Addictive Behavior. 1st Edn., Guilford Press, New York, ISBN-13: 9780898624694, pp: 348.

Nishith, P., K.T. Mueser and P. Gupta, 1994. Personality and hallucinogen abuse in a college population from India. Personal. Individual Diff., 17: 561-563. DOI: 10.1016/0191-8869(94)90093-0

Ramzi, N.N. and V. Naimy, 2010. Using regression to establish weights for a set of composite equations through a numerical analysis approach: a case of admission criteria to a college. J. Math. Stat., 6: 300-305. DOI: 10.3844/jmssp.2010.300.305

Russo, N.F. and S.B. Sobel, 1981. Sex differences in the utilization of mental health facilities. Profess. Psychol., 12: 7-19. DOI: 10.1037/07357028.12.1.7

Sansone, J., 1980. Retention patterns in a therapeutic community for the treatment of drug abuse. Int. J. Addictions, 15: 711-736. PMID: 7419304

Schober, R. and H.M. Annis, 1996. Barriers to helpseeking for change in drinking: A gender-focused review of the literature. Addictive Behav., 21: 81-92. DOI: 10.1016/0306-4603(95)00041-0

Schutz, C.G., E. Rapiti, D. Vlahov and J.C. Anthony, 1994. Suspected determinants of enrollment into detoxification and methadone maintenance treatment among injecting drug users. Drug Alcohol Dependence, 36: 129-138. DOI: 10.1016/0376-8716(94)90095-7

Shahrazad, W.S.W., Z.M. Lukman, A.R.R. Murni, Z. Arifin and A.Z. Zainah et al., 2010. Personality traits and readiness to change among drug addicts in Malaysia. Res. J. Applied Sci., 5: 263-266. DOI: 10.3923/rjasci.2010.263.266

Simpson, D.D., G.W. Joe and G.A. Rowan-Szal, 1997. Drug abuse treatment retention and process effects on follow-up outcomes. Drug Alcohol Dependence, 47: 227-235. DOI: 10.1016/S03768716(97)00099-9

Thom, B., 1987. Sex differences in help-seeking for alcohol problems-2. Entry into treatment. British J. Add., 82: 989-997. DOI: 10.1111/j.13600443.1987.tb01559.x

Walitzer, K.S. and G.J. Connors, 1997. Gender and treatment of alcohol related problems. In: Gender and alcohol: Individual and social perspectives, Wilsnack, R.W. and S.C. Wilsnack (Eds.). Rutgers University Press, USA., ISBN-13: 9780911290554, pp: 445-461.

Weisdorf, T., T.V. Parran Jnr., A. Graham and C. Snyder, 1999. Comparison of pregnancy-specific interventions to a traditional treatment program for cocaine-addicted pregnant women. J. Substance Abuse Treat., 16: 39-45. PMID: 9888120 
Am. J. Applied Sci., 8 (2): 134-140, 2011

Weisner, C. and L. Schmidt, 1992. Gender disparities in treatment for alcohol problems. JAMA, 268: 1872-1876. PMID: 1328695 http://www.ncbi.nlm.nih.gov/pubmed/1328695 Wetherington, C.L., 1999. Drug addiction research and the health of women. 1st Edn., Diane Pub Co, UK., ISBN-10: 0788180533, pp: 142.
Yampolskiy, R.V., 2008. Behavioral modeling: An overview. Am. J. Applied Sci., 5: 496-503. DOI: 10.3844/ajassp.2008.496.503

Zebun, N.K., 2009. Cognitive and non-cognitive characteristics as determinants of success in professional courses at undergraduate stage. J. Soc. Sci., 5: 212-215. DOI: 10.3844/jssp.2009.212.215 